DOI: $10.30519 /$ ahtr. 819112

Advances in Hospitality and Tourism Research (AHTR)

\title{
THE EFFECT OF COLOR IN AIRBNB LISTINGS ON GUEST RATINGS
}

\author{
Hyunkyu JANG ${ }^{1}$ \\ Department of Marketing, Governors State University, USA \\ ORCID: 0000-0001-9081-1373
}

\begin{abstract}
The present research analyzes the color scheme of more than 30,000 photos in Airbnb listings in New York City to examine the relationship between the color schemes of Airbnb properties and guest ratings. The research finds that Airbnb listings with black as the dominant background or foreground color and those with magenta as the accent color received lower guest ratings than listings with other colors. This research also finds significant interaction effects of color, saturation, and value (brightness) of accent colors, indicating that it is important to select an optional saturation and value for each color.
\end{abstract}

\author{
Article History \\ Received 31 October 2020 \\ Revised 20 July 2021 \\ Accepted 26 July 2021 \\ Published online 28 July 2021 \\ Keywords \\ Airbnb \\ guest star ratings \\ photos \\ color \\ hue \\ saturation
}

\section{INTRODUCTION}

Peer-to-peer sharing platforms such as Airbnb, Uber, and Zipcar have proliferated in the last decade. In particular, Airbnb has become a significant force in the tourism and hospitality industry. Over 150 million total guests have stayed at accommodations booked through Airbnb since it was founded in 2008 (Allyn, 2020). Airbnb currently offers over 7 million rental listings worldwide in 220 countries and regions (Barker, 2020).

The growing influence of Airbnb has led to an extensive body of literature exploring various factors related to Airbnb. A stream of prior research has used Airbnb photos to infer information from those photos such as the host's trustworthiness (Ert et al., 2016), facial attractiveness (Jaeger et al., 2019), facial expressions (Fagerstrøm et al., 2017), and race (Jaeger et al., 2019). Researchers have then examined the relationship between that inferred information and host/guest behavior. They found that

\footnotetext{
${ }^{1}$ Address correspondence to Hyunkyu Jang (Ph.D.), Department of Marketing, College of Business, Governors State University, USA. E-mail: hjang@govst.edu
} 
guests would prefer to rent from hosts with positive (vs. negative) facial expressions (Fagerstrøm et al., 2017) and that hosts who were perceived as more (vs. less) trustworthy, attractive, or white tended to charge higher prices for their properties (Ert et al., 2016; Jaeger et al., 2019). However, these studies only used profile photos of Airbnb hosts, but not of the properties. Although the photos of properties may provide useful information about properties such as the color schemes of properties, little research has explored the influence of that information on guest satisfaction.

A wealth of prior research on tourism has investigated the impact of colors of hotel rooms (Lee et al., 2018; Siamionava et al., 2018), hotel lobbies (Countryman \& Jang, 2006), and hotel bars (Lin, 2009) on guest emotions and satisfaction. For example, color was identified as the most influential factor affecting guest impressions of the ambience of hotel lobbies (Countryman \& Jang, 2006). Hotel rooms with cool colors such as blue resulted in participant rankings that were more positive than hotel rooms with warm colors such as red in terms of guest wellbeing (Lee et al., 2018). Participants responded that they would enjoy staying in blue hotel rooms more than in red rooms (Siamionava et al., 2018). Although these studies have addressed the influence of colors in various ways, they have some limitations. First, the context has been limited to hotel facilities and does not include accommodation-sharing platforms. It is yet to be determined whether past findings on the influence of color applies in the peer-to-peer accommodation context. Second, all prior studies have used either experiment or survey methods. Respondents were exposed to visual materials (e.g., a photo of a hotel room) for a short time, whereas in reality, guests stay in a room for a longer time and could unconsciously get habituated to color stimuli. Participant responses based on imagined reaction to photos may not accurately predict responses to lived experiences. Third, color manipulation in experiments could be extreme and artificial, with the entire color scheme of rooms appearing reddish or bluish, which rarely occurs in actual room color schemes. Someone who indicated that he would not like to stay in an entirely reddish room might indicate a preference for a room with white walls and red accents (e.g., cushion, vase) over a room with white walls and blue accents. The use of extreme stimuli might limit ecological validity. Fourth, most past studies have compared two color schemes (e.g., red versus blue or warm colors versus cool colors). Moreover, those studies have only focused on one dimension of color (hue) rather than on different dimensions of color (hue, saturation, and value). Even though a color is red in hue, differences in saturation and value (brightness) could lead to differences in guest 
preferences. Although Siamionava et al. (2018) has considered three dimensions, they only investigated the influence of each dimension on psychological outcomes such as the dominance and arousal that participants experienced, but did not investigate the influence on guest evaluations.

The present research aimed to fill this research gap by analyzing guest rating data on actual Airbnb stays in New York City. More specifically it analyzed the photos of Airbnb property postings to obtain color information on those properties, using Microsoft Azure's Artificial Intelligence and Machine Learning service. The research then examined the impact of those property color schemes on guest star ratings. The purpose of the present research is to address the discussed limitations in past findings in the following ways. First, since the context is an accommodation-sharing platform, the present research can determine whether past findings apply to accommodation-sharing platforms. Second, the guest evaluations the present research analyzed were made by guests who have actually stayed in Airbnb properties and were naturally exposed to color stimuli. The data can better identify the relationship between guest evaluations and colors. Third, the present research separately analyzed dominant background color, dominant foreground color, and accent colors in an Airbnb property. The results of this analysis can provide more detailed guidelines for room color design. Fourth, the present research analyzed the different dimensions of color (hue, saturation, and value). Therefore, the interaction effects of different dimensions could be obtained. In other words, the present research addressed which saturation or value within a single hue would lead to a better guest rating. The present research sought to answer the following research questions: 1) Do past findings that blue rooms are preferable to red rooms in the hotel context hold true in accommodation-sharing platforms? 2) Which background, foreground, and accent colors result in better guest evaluations than other background, foreground, and accent colors?

\section{LITERATURE REVIEW}

Most prior research has split colors into two categories, warm colors (red and yellow) and cool colors (blue and green) and contrasted the effect of red versus blue on various affective, cognitive, or behavioral outcomes. Red has been found to be more arousing than blue or green (Jacobs \& Hustmyer, 1974; Wilson, 1966). Anger has been found to increase the blood flow in the face and redden the face (Drummond \& Quah, 2001), enhancing the performance of athletes (Coleman \& Williams, 2013). An analysis of 
Olympic combat sports (e.g., boxing, taekwondo, and wrestling) revealed that players wearing red won more games than those wearing blue even though players were randomly assigned to red or blue outfits (Hill \& Barton, 2005). Similarly, red has been found to boost performance in team sports such as soccer more than other colors (Attrill et al., 2008). Hill and Barton (2005) suggested that redness during aggressive interaction might serve as a signal of dominance. When viewing opponents wearing red (versus blue), observers are more likely to feel that opponents are more dominant and threatening (Feltman \& Elliot, 2011).

Although red has been found to exert a positive effect on athletic performance, red has also been found to undermine performance in some achievement contexts (e.g., testing). Viewing red impairs performance on an IQ test compared to viewing green or achromatic colors such as gray (Elliot et al., 2007). Elliot et al. (2007) proposed that red is often associated with danger and failure (e.g., stop signs, incorrect answers marked with red ink) and activates the motivation to avoid failure, which negatively influences performance by causing anxiety and distraction. Mehta and Zhu (2009) suggested that the influence of red (versus blue) color on performance depends on the type of task rather than being either completely positive or negative. According to Mehta and Zhu (2009), red evokes an avoidance motivation and improves performance on detailoriented tasks (e.g., proofreading), whereas blue evokes an approach motivation and enhances performance on creative tasks (e.g., generating as many creative uses of a brick as participants could).

The influence of color has been actively explored by consumer behavior researchers. Consumers associated blue with trustworthiness; red with love; and black with power (Jacobs et al., 1991). Some studies have found that consumers respond to blue more positively than to red. For example, a blue retail environment produced greater pleasure and greater likelihood that the consumer would buy a TV than a red shopping environment (Bellizzi \& Hite, 1992). Stores with blue-colored exteriors led to lower perceived crowding, higher perceived service quality, and more favorable shopping intentions than stores with orange-colored exteriors (Yüksel, 2009). Stores with blue interiors led to more favorable evaluations and greater purchase intentions than stores with orange interiors (Babin et al., 2003). Consumers selected blue most frequently as the best match for still and sparkling water bottles over red or green bottles (Ngo et al., 2012). However, other studies have suggested that the influence of color on consumer preferences depends on the type of product. Bottomley and Doyle (2006) suggested that consumers view blue as more appropriate for 
logos of functional products (e.g., car tires, power tools) and red as more appropriate for logos of sensory-social products (e.g., amusement parks, perfumes). Hanss et al. (2012) investigated the appropriateness of color for different car types, finding that compact cars, sports cars, and convertibles were most frequently associated with red; sedans with black; vans and station wagons with purple-blue; and all-terrain vehicles with green. These findings indicate that the effect of color is dependent on the consumption context.

As the importance of the internet to business increases, consumer research has focused on e-atmospherics (e.g., Eroglu et al., 2003). Eatmospherics are defined as "the conscious designing of web environments to create positive effects in users in order to increase favorable consumer responses" (Dailey, 2004) and color has been explored as one of the eatmospheric cues. For example, web sites with a blue color scheme were perceived to be more trustworthy than those with red or green color schemes (Alberts \& Van Der Geest, 2011; Lee \& Rao, 2010). Blue elicited more relaxed feelings than red or yellow, which led to faster perceived speed of a photo download on a real-estate website, more favorable attitudes toward the site, and greater likelihood of recommending the site to a friend (Gorn et al., 2004). Consumers reported they were more likely to purchase a book on a blue website than on a green website (Lee \& Rao, 2010). These findings may seem to indicate that blue is more positive in the online shopping context. However, as shown earlier in other consumer research, the influence of color in online settings would seem to depend on the type of product. On websites selling jewelry and accessories (e.g., necklaces and watches), the color red led to higher arousal, which in turn led to greater behavioral intentions than blue (Wu et al., 2008). Although consumer responses have varied, emotional reactions to blue and red were consistent across different studies: blue elicits low arousal feelings (e.g., calm) and red elicits high arousing feelings (e.g., excitement). This may imply that the fit between level of arousal and the type of product/service is a critical factor determining consumer responses. Consistent with this prediction, Jiang and Wang (2006) suggested that high arousal increases service quality and satisfaction in the hedonic service context, but not in the utilitarian service context (Jiang \& Wang, 2006).

A significant amount of research has demonstrated that the preferences, influences, and meanings of different colors also varies by country/culture, gender, and age (Aslam, 2006; Chebat \& Morrin, 2007; Funk \& Ndubisi, 2006; Jacobs et al., 1991; Madden et al., 2000; Puccinelli et al., 2013; Yildirim et al., 2007). For example, Jacobs et al. (1991) found that 
purple was associated with inexpensive products in the U.S., whereas it is associated with expensive products in East Asian countries. Madden et al. (2000) examined consumer preferences for colors in eight countries, reporting that preferences for blue, brown, gold, orange, purple, and yellow varied across countries, whereas preferences for black, green, red, and white did not. Male consumers are more likely than female consumers to perceive products as being sold at a lower price when prices are presented in red versus in black (Puccinelli et al., 2013). This implies that the location of travel destinations and tourist demographics need to be considered in examining the influence of color in the tourism context.

In summary, the influence of colors is context-dependent. It varies depending on country/ culture, age, gender, the type of product/service, and the type of task. Accommodation-sharing platforms like Airbnb and hotels are similar in both providing hospitality services; however, the two may differ in various aspects, including the demographic characteristics of guests (e.g., income, age), room prices, trust in service providers, and service quality expectations. Therefore, findings in the hotel context may not apply to accommodation-sharing platforms. The present research attempted to examine the influence of colors on guest evaluations in the newly emerging online accommodation context.

\section{METHODOLOGY}

\section{Airbnb Data}

An Airbnb dataset was obtained from Inside Airbnb². The present research chose to analyze Airbnb data from New York City listings because many tourists visit New York City and prior research has analyzed Airbnb data from New York City (e.g., Jaeger et al., 2019). The dataset for the present research contained detailed information about all 49,530 New York City listings posted on Airbnb on June $8^{\text {th }}, 2020$.

The present research used guest star ratings as the dependent variable. Out of the 49,530 listings, 37,243 listings that had guest ratings were included in the analyses. The dataset contained guest ratings on a 100point scale, which had been calculated by multiplying raw star ratings on a 5 -point scale by 20 , so the guest ratings reported in the current article were also on a 100-point scale. The dataset also provided the URL address of the cover photo of each listed property. The cover photo is the photo displayed in search results and the largest and the first photo of five photos displayed

2 http://insideairbnb.com 
on the page for each listing. Those cover photos were used to analyze the color scheme of each listed property.

\section{Color Analysis}

Microsoft Azure's Computer Vision service was used to analyze the color scheme of each property and Python programming language was used to request analyses for the 37,243 cover photos. Azure's Computer Vision service analyzes images, providing three types of color information: the dominant background color, dominant foreground color, and accent color.

Since the present research focuses on the interior colors of properties, only photos depicting the inside of properties were included for analyses. Azure's Computer Vision categorizes photos information according to content, such as "indoor" or "outdoor," so those categorized as indoor photos were used as depicting the interior of the properties. Photos categorized by Computer Vision as black and white photos were excluded from the analyses.

\section{RESULTS}

Out of the 37,243 listings with guest ratings, 48 photos were excluded: 37 photos were black and white and Microsoft's Azure was not able to provide color photo information for 11 other photos. This left 37,195 color photos. Out of the remaining 37,195 photos, 32,237 photos depicted the indoor images of properties, so the 32,237 photos were included for analyses. Guest rating was the dependent variable for all the following analyses.

\section{Background and Foreground Color Analysis}

White was most frequently identified as both the dominant background and foreground color (see Table 1). Grey, brown, and black followed white as the next most common dominant background and foreground colors, in that order. These four colors accounted for the dominant background colors for $97.86 \%$ of the listings and for the dominant foreground colors for $98.1 \%$ of the listings. Each of the other eight colors identified as dominant background or foreground colors accounted for only less than $1 \%$ of listings.

To examine the relationship between background colors and guest ratings, an ANOVA with background color as the independent variable was performed. The results indicated that background color was strongly associated with guest ratings $(M=93.87, S D=9.17 ; F(11,32,225)=4.03, p$ 
$<.0001)$. Post-hoc multiple comparisons using the Tukey-Kramer test showed at the 5\% significance level that the only significant differences affecting guest ratings were that grey and brown backgrounds were more positively associated with high guest ratings than black.

A similar ANOVA analysis performed for foreground colors demonstrated that foreground colors were also strongly associated with guest ratings $(F(11,32,225)=3.59, p<.0001)$. Post-hoc multiple comparisons using the Tukey-Kramer test showed that at the 5\% significance level the only significant differences affecting guest ratings were that grey and white foregrounds were more positively associated with high guest ratings than black. In analyses for both background and foreground colors, black was negatively associated with guest ratings.

Table 1. Dominant background and foreground colors and guest ratings

\begin{tabular}{ccccccccc}
\hline \multirow{2}{*}{ No. } & \multicolumn{3}{c}{ Background colors } & & \multicolumn{3}{c}{ Foreground colors } \\
\cline { 2 - 5 } \cline { 6 - 8 } \cline { 6 - 8 } & Colors & N & Ratings & & Colors & N & Ratings \\
\hline 1 & White & 10,212 & 93.82 & & White & 12,112 & $93.94^{\mathrm{a}}$ \\
2 & Grey & 9,699 & $94.06^{\mathrm{a}}$ & & Grey & 8,727 & $94.09^{\mathrm{b}}$ \\
3 & Brown & 8,350 & $94.02^{\mathrm{b}}$ & & Brown & 6,374 & 93.93 \\
4 & Black & 3,287 & $93.35^{\mathrm{ab}}$ & & Black & 4,410 & $93.38^{\mathrm{ab}}$ \\
5 & Yellow & 236 & 92.75 & & Red & 176 & 92.20 \\
6 & Orange & 185 & 93.34 & & Yellow & 147 & 91.88 \\
7 & Red & 109 & 93.75 & & Orange & 99 & 93.82 \\
8 & Pink & 73 & 93.96 & & Pink & 74 & 92.91 \\
9 & Blue & 33 & 91.00 & & Blue & 66 & 91.41 \\
10 & Green & 30 & 89.30 & & Green & 29 & 92.00 \\
11 & Teal & 17 & 87.71 & & Teal & 16 & 93.00 \\
12 & Purple & 6 & 86.00 & & Purple & 7 & 97.57 \\
\hline
\end{tabular}

\section{Accent Colors}

Unlike background and foreground colors, Azure's Computer Vision provides HEX (Hexadecimal) color code $^{3}$ rather than color names such as white or black for accent colors. The present research transformed the HEX code of accent colors into a hue, saturation, and value (HSV) color space to analyze those three independent attributes of colors, as had prior research (e.g., Gorn et al., 1997; Siamionava et al., 2018; Thompson et al., 1992). Hue indicates color types such as red, green, or blue. Saturation indicates the

\footnotetext{
${ }^{3}$ A hexadecimal color code consists of six characters, every two characters ranging between 00 and FF to represent minimum versus maximum red, green, and blue components of colors (e.g., \# 0000FF to indicate blue).
} 
colorfulness or purity of a color: the lower the saturation, the more faded a color appears. Value indicates the brightness of a color. Saturation and value are expressed as percentages ranging from $0 \%$ to $100 \%$, whereas hue is expressed as degrees from $0^{\circ}$ to $360^{\circ}$ on a color wheel, with both end values of hue indicating red $\left(0^{\circ}\right.$ refers to red; $120^{\circ}$ green; $240^{\circ}$ blue; and $360^{\circ}$ red again).

To understand the influence of accent colors on guest ratings, the influence of color types indicated by hue degrees was first investigated and then the interaction effects were examined between color types, saturation, and value. Based on hue degrees, accent colors were divided into six color groups. Two common methods for grouping colors were used: regular partitioning and color space clustering (Leow \& Li, 2004).

Adopting the first grouping method, accent colors were partitioned into six color bins with equal intervals of 60 hue degrees (e.g., $30^{\circ}$ to $90^{\circ}$ assigned to the yellow color bin; see the "Regular partitioning" column in Table 2 for the color bins and hue ranges). An ANOVA with color bin as the independent variable was performed to examine the relationship between the six accent color bins and guest ratings. The results showed that guest ratings differed across the six accent color bins $(F(5,32,231)=2.62, p=.0224)$. Post-hoc multiple comparisons using the Tukey-Kramer test revealed at the $5 \%$ significance level that listings with magenta (hue degrees of $270^{\circ} \sim 330^{\circ}$ ) as the accent color had significantly lower guest ratings than listings with red, yellow, cyan or blue as the accent color.

Table 2. Accent colors and guest ratings

\begin{tabular}{|c|c|c|c|c|c|c|c|c|c|}
\hline \multirow{2}{*}{ No. } & \multicolumn{3}{|c|}{ Regular partitioning } & \multicolumn{3}{|c|}{ K-means for 6 clusters } & \multicolumn{3}{|c|}{ K-means for 7 clusters } \\
\hline & Colors & $\mathbf{N}$ & Ratings & Colors & $\mathbf{N}$ & Ratings & Colors & $\mathbf{N}$ & Ratings \\
\hline 1 & $\begin{array}{c}\text { Red } \\
\left(330^{\circ} \sim 30^{\circ}\right)\end{array}$ & 16,012 & $93.9^{a}$ & $\begin{array}{c}\text { Red } \\
\left(322^{\circ} \sim 360^{\circ}\right)\end{array}$ & 1,347 & $93.6^{\mathrm{a}}$ & $\begin{array}{c}\text { Red } \\
\left(331^{\circ} \sim 360^{\circ}\right)\end{array}$ & 1,268 & $93.6^{\mathrm{a}}$ \\
\hline 2 & $\begin{array}{l}\text { Yellow } \\
\left(30^{\circ} \sim 90^{\circ}\right)\end{array}$ & 11,499 & $94.0^{\mathrm{a}}$ & $\begin{array}{c}\text { Red-orange } \\
\left(0^{\circ} \sim 35^{\circ}\right)\end{array}$ & 20,166 & $93.9^{a}$ & $\begin{array}{l}\text { Red-orange } \\
\qquad\left(0^{\circ} \sim 31^{\circ}\right)\end{array}$ & 15,592 & $93.9^{a}$ \\
\hline 3 & $\begin{array}{c}\text { Green } \\
\left(90^{\circ} \sim 150^{\circ}\right)\end{array}$ & 205 & 94.1 & $\begin{array}{l}\text { Yellow- } \\
\text { green } \\
\left(35^{\circ} \sim 101^{\circ}\right)\end{array}$ & 6,175 & $93.9^{a}$ & $\begin{array}{l}\text { Yellow } \\
\left(31^{\circ} \sim 74^{\circ}\right)\end{array}$ & 10,348 & $93.9^{a}$ \\
\hline 4 & $\begin{array}{c}\text { Cyan } \\
\left(150^{\circ} \sim 210^{\circ}\right)\end{array}$ & 2,477 & $93.8^{\mathrm{a}}$ & $\begin{array}{c}\text { Green } \\
\left(101^{\circ} \sim 182^{\circ}\right)\end{array}$ & 296 & $93.1^{\mathrm{a}}$ & $\begin{array}{c}\text { Green } \\
\left(75^{\circ} \sim 154^{\circ}\right)\end{array}$ & 515 & $94.6^{\mathrm{a}}$ \\
\hline 5 & $\begin{array}{c}\text { Blue } \\
\left(210^{\circ} 270^{\circ}\right)\end{array}$ & 1,878 & $93.8^{\mathrm{a}}$ & $\begin{array}{c}\text { Blue } \\
\left(182^{\circ} \sim 250^{\circ}\right)\end{array}$ & 4,110 & $93.9^{\mathrm{a}}$ & $\begin{array}{c}\text { Cyan } \\
\left(155^{\circ} 210^{\circ}\right)\end{array}$ & 2,370 & $93.8^{\mathrm{a}}$ \\
\hline 6 & $\begin{array}{l}\text { Magenta } \\
\left(270^{\circ} \sim 330^{\circ}\right)\end{array}$ & 166 & $91.5^{\mathrm{b}}$ & $\begin{array}{l}\text { Magenta } \\
\left(251^{\circ} \sim 321^{\circ}\right)\end{array}$ & 143 & $90.2^{\mathrm{b}}$ & $\begin{array}{c}\text { Blue } \\
\left(210^{\circ} 265^{\circ}\right)\end{array}$ & 1,956 & $93.9^{a}$ \\
\hline 7 & & & & & & & $\begin{array}{l}\text { Magenta } \\
\left(266^{\circ} \sim 331^{\circ}\right)\end{array}$ & 188 & $91.2^{\mathrm{b}}$ \\
\hline
\end{tabular}

Note: Guest ratings for color groups with the "a" superscript are significantly greater than those with the " $\mathrm{b}$ " superscript within each column. The numbers in parentheses indicate the hue range measured in degrees for each color group. 
For the second grouping method, the K-means clustering algorithm (MacQueen, 1967) was used. The clustering algorithm clusters accent colors that are close to each other in hue degree. Because of the unique and circular nature of hue data, one limitation of the algorithm in dealing with hue degrees is that the algorithm never classifies the hue of $0^{\circ}$ and the hue of $360^{\circ}$ into the same cluster, although they are exactly the same hue of red. Note that when using the regular partitioning method, the red color bin included hue degrees ranging from $330^{\circ}$ to $360^{\circ}$ and from $0^{\circ}$ to $30^{\circ}$, while the clustering algorithm would assign two separate red clusters for each range, one ranging from $330^{\circ}$ to $360^{\circ}$ (red-magenta) and the other ranging from $0^{\circ}$ to $30^{\circ}$ (red-orange). To supplement this limitation, two separate Kmeans clustering analyses were performed, one dividing accent colors into six clusters and one dividing them into seven clusters (see the two "Kmeans" columns in Table 2 for details). The seven clusters looked to be more similar in terms of hue ranges to the six bins from the regular partitioning method than were the six clusters. Next, two separate ANOVA analyses were performed, one with the six clusters and the other with the seven clusters. The results of both analyses revealed a significant effect of accent colors $(F(5,32,231) s>3.45$, ps $<.0021)$. Two separate post-hoc TukeyKramer tests for the six clusters and seven clusters confirmed that the magenta color had a detrimental impact on guest ratings at the $5 \%$ significance level, consistent with the results using the six bins from the regular portioning method.

Next, to examine the interaction effects of the six color bins (hues) from regular partitioning, saturation, and value, an ANOVA was performed (See Appendix for the full list of independent variables). The quadratic terms of saturation and those of value were included as independent variables because the relationship between saturation/value and guest ratings might be curvilinear (Guilford \& Smith, 1959), implying that people's sensitivity to changes in saturation and/or value may differ before or after a certain threshold of saturation and/or value. The results demonstrated that the interaction between the quadratic term of saturation, the quadratic term of value, and the color bin was significant $(F(5,32,231)=$ 2.90, $p=.0128$; See Appendix for all the results). This indicates that the relationships between saturation/value and guest ratings are indeed quadratic and moreover the relationships depend on color type. Figure 1 illustrates the relationship between saturation, value, and guest ratings for each color bin. For example, for cyan, when the value was high, the more saturated the accent color was, the higher the guest ratings, whereas saturation did not influence guest ratings when the value was low. As to 
magenta, magenta was not always associated with low guest ratings, but rather a highly saturated magenta led to high guest ratings.
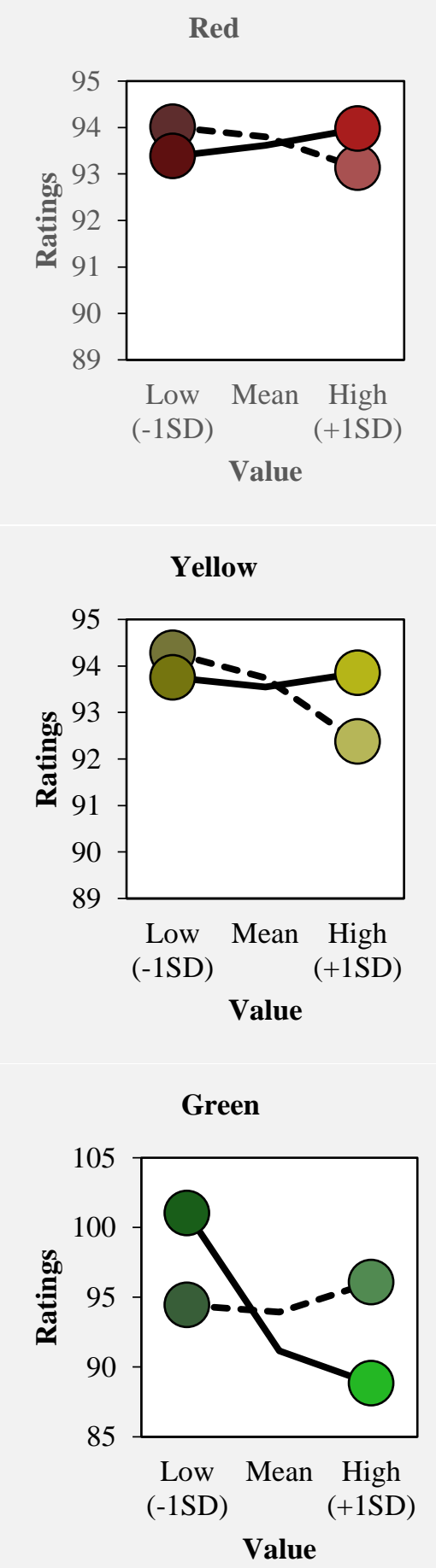

High Saturation (+1SD)
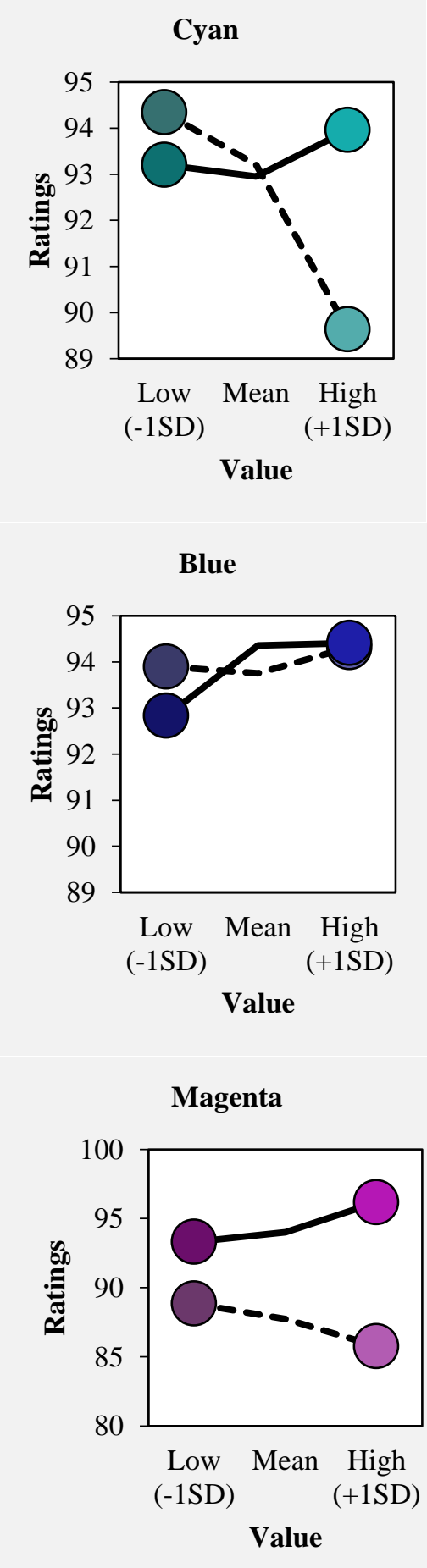

Low saturation (-1SD)

Figure 1. The relationship of accent color bins, saturation, value to guest ratings 


\section{DISCUSSION}

The investigation of $+30,000$ Airbnb cover photos provided three findings. First, magenta as an accent color led to lower guest ratings in general. This reflects the finding that Americans associated purple with "inexpensive" (Jacobs et al., 1991). In contrast, in the same study, East Asians associated purple with "expensive." This may imply that color preferences on Airbnb properties differ by country. Since past research has demonstrated cultural differences in preference, meanings, and associations with colors (Aslam, 2006; Chebat \& Morrin, 2007; Jacobs et al., 1991; Madden et al., 2000), future research needs to explore the effect of color on guest evaluations in other cities. Second, the influence of accent color on guest ratings depended on the extent of saturation and value, signifying the importance of selecting an optimal extent of saturation and value for each color type. More specifically, some colors such as red, yellow, and blue were relatively independent of the degree of saturation and value, whereas other colors such as cyan, green, and magenta were more dependent on the degree of saturation and value. This implies that hosts need to be more careful about saturation and value when selecting items that are cyan, green, or magenta. Third, black background and foreground colors led to lower guest ratings. Further investigation of Airbnb photos that were categorized as having a black background or foreground color revealed that those Airbnb properties typically had black bed sheets, sofas, rugs, chairs, televisions, or dressers. The atmosphere created by a greater number of black items might have led customers to be less satisfied while staying there or to have drawn other negative inferences. Future research can explore this topic.

The present research contributes to the literature on the influence of colors on guests in the hospitality industry (Countryman \& Jang, 2006; Lee et al., 2018; Lin, 2009; Siamionava et al., 2018). Previous research has demonstrated the importance of colors, relying on responses of participants who were placed in hypothetical situations, mainly through surveys or experiments. The present research complements these previous findings by reporting the significant role of colors on actual guest ratings measured in real situations. These findings also provide a holistic view of the actual color composition of Airbnb properties. Warm colors (i.e., red, red-orange, yellow) were used more frequently than cool colors (i.e., blue, green, cyan) as accent colors although guest ratings did not differ for warm and cool colors. Also, background and foreground mostly consisted of achromatic colors (white, grey, and black) and brown, since walls and furniture are predominantly those colors. This indicates that the dominant color of rooms 
was rarely reddish or bluish, but rather rooms tend to have red or blue only as accent colors.

Most prior studies have compared cool colors to warm colors and found more a favorable effect from cool colors in terms of guest wellbeing (Lee et al., 2018) or greater enjoyment (Siamionava et al., 2018). In contrast, the current analyses did not find a significant difference between cool and warm colors. Several reasons may explain this lack of difference. First, differences in demographic characteristics between Airbnb guests and hotel guests might provide an explanation. Most Airbnb users are young people under 35 years old (Thompson, 2018). If Airbnb guests were younger than hotel guests and young people were more likely to prefer an ambience of high arousal (i.e., exciting) over low arousal (i.e., calming), rooms with warm colors would have received better evaluations in the Airbnb context than in the hotel context. As a result, there is no significant difference between warm and cool colors in the Airbnb context although cool colors were found to be preferred in the hotel context. Second, the regional characteristics of New York City might have caused the lack of any significant difference. Past studies did not specify the location of hotels in the scenarios, whereas in the present research, the location was specific and it was New York City. People who have visited New York City perceive the city to be highly arousing rather than relaxing (Phillips \& Jang, 2010). The city is also known as one of the most exciting cities in the world (NBC New York, 2019). Tourists who choose the city as their travel destination tend to want to experience excitement rather than relaxation (Goossens, 2000), which might result in better evaluations for properties with warm colors. If this is the case, guest ratings for listings with warm colors should be lower in regions that tourists visit to experience relaxation. Third, differences in the salience of color could be the reason. In previous studies, the color factor may have been made more salient to participants. Participants in previous studies completed questions about dependent variables after responding to measures about the relationship between colors and emotions or after being shown stimuli that were quite different except as to color. This might have led participants to pay greater attention to or place greater weight on color in responding to dependent variables. Therefore, even if a difference between bluish and reddish colors existed in Airbnb listings, the magnitude of the difference captured by guest ratings might not be as large as in data from previous studies.

The present research has several limitations that can serve as valuable directions for future research. First, the region was limited to one city in the United States. Future research could expand the regional scope 
to multiple cities in the U.S. or to other countries and investigate similarities and differences between cities and countries in the influence of color on guest satisfaction. Second, the present research focused on the colors on the inside of rental properties (86.7\% of all images collected from the postings), excluding from analysis the photos depicting some outdoor areas $(13.3 \%$ of all images). Future research can address the influence on guest satisfaction of the color of the exterior of properties. Moreover, the influence of color on the inside may be different for different rooms. For example, red may have positive effects in kitchens, but negative effects in bathrooms. Future research can distinguish indoor areas more specifically and analyze them separately. Third, the present research analyzed guest ratings only at a certain point of time. However, the influence of a certain color may change over time as trendy colors in the fashion industry change. It is possible that a certain color that was viewed favorably in the past is now viewed as outdated. Therefore, it is also worth exploring the influence of color on guest satisfaction over a long-time horizon.

One of the key implications from the present research is that the influence of color is more complicated than the simple dichotomous redblue relationship in prior research might have assumed. The current findings can serve as a starting point for future research on the different influences of various colors on guest satisfaction.

\section{REFERENCES}

Alberts, W. A., \& Van Der Geest, T. M. (2011). Color matters: Color as trustworthiness cue in web sites. Technical Communication, 58(2), 149-160.

Allyn, B. (2020, April 28). For Airbnb, 2020 was supposed to be a banner year. Then the pandemic hit. Retrieved July 14, 2020, from NPR.org website: https://www.npr.org/2020/04/28/846780052/for-airbnb-2020-was-supposed-to-bea-banner-year-then-the-pandemic-hit

Aslam, M. M. (2006). Are you selling the right colour? A cross-cultural review of colour as a marketing cue. Journal of Marketing Communications, 12(1), 15-30.

Attrill, M. J., Gresty, K. A., Hill, R. A., \& Barton, R. A. (2008). Red shirt colour is associated with long-term team success in English football. Journal of Sports Sciences, 26(6), 577-582.

Babin, B. J., Hardesty, D. M., \& Suter, T. A. (2003). Color and shopping intentions: The intervening effect of price fairness and perceived affect. Journal of Business Research, $56(7), 541-551$.

Barker, G. (2020, February 21). The Airbnb effect on housing and rent. Retrieved July 14, 2020, from Forbes website: https://www.forbes.com/sites/garybarker/2020/02/21/the-airbnb-effect-onhousing-and-rent/\#2b99e9bb2226

Bellizzi, J. A., \& Hite, R. E. (1992). Environmental color, consumer feelings, and purchase likelihood. Psychology \& Marketing, 9(5), 347-363. 
Bottomley, P. A., \& Doyle, J. R. (2006). The interactive effects of colors and products on perceptions of brand logo appropriateness. Marketing Theory, 6(1), 63-83.

Chebat, J.-C., \& Morrin, M. (2007). Colors and cultures: Exploring the effects of mall décor on consumer perceptions. Journal of Business Research, 60(3), 189-196.

Coleman, N. V., \& Williams, P. (2013). Feeling like my self: Emotion profiles and social identity. Journal of Consumer Research, 40(2), 203-222.

Countryman, C. C., \& Jang, S. (2006). The effects of atmospheric elements on customer impression: The case of hotel lobbies. International Journal of Contemporary Hospitality Management, 18(7), 534-545.

Dailey, L. (2004). Navigational web atmospherics: Explaining the influence of restrictive navigation cues. Journal of Business Research, 57(7), 795-803.

Drummond, P. D., \& Quah, S. H. (2001). The effect of expressing anger on cardiovascular reactivity and facial blood flow in Chinese and Caucasians. Psychophysiology, 38(2), 190-196.

Elliot, A. J., Maier, M. A., Moller, A. C., Friedman, R., \& Meinhardt, J. (2007). Color and psychological functioning: The effect of red on performance attainment. Journal of Experimental Psychology: General, 136(1), 154.

Eroglu, S. A., Machleit, K. A., \& Davis, L. M. (2003). Empirical testing of a model of online store atmospherics and shopper responses. Psychology \& Marketing, 20(2), 139-150.

Ert, E., Fleischer, A., \& Magen, N. (2016). Trust and reputation in the sharing economy: The role of personal photos in Airbnb. Tourism Management, 55, 62-73.

Fagerstrøm, A., Pawar, S., Sigurdsson, V., Foxall, G. R., \& Yani-de-Soriano, M. (2017). That personal profile image might jeopardize your rental opportunity! On the relative impact of the seller's facial expressions upon buying behavior on Airbnb ${ }^{\mathrm{TM}}$. Computers in Human Behavior, 72, 123-131.

Feltman, R., \& Elliot, A. J. (2011). The influence of red on perceptions of relative dominance and threat in a competitive context. Journal of Sport and Exercise Psychology, 33(2), 308-314.

Funk, D., \& Ndubisi, N. O. (2006). Colour and product choice: A study of gender roles. Management Research News, 29(1/2), 41-52.

Goossens, C. (2000). Tourism information and pleasure motivation. Annals of Tourism Research, 27(2), 301-321.

Gorn, G. J., Chattopadhyay, A., Sengupta, J., \& Tripathi, S. (2004). Waiting for the web: How screen color affects time perception. Journal of Marketing Research, 41(2), 215225.

Gorn, G. J., Chattopadhyay, A., Yi, T., \& Dahl, D. W. (1997). Effects of color as an executional cue in advertising: They're in the shade. Management Science, 43(10), 1387-1400.

Guilford, J. P., \& Smith, P. C. (1959). A system of color-preferences. The American Journal of Psychology, 72(4), 487-502.

Hanss, D., Böhm, G., \& Pfister, H.-R. (2012). Active red sports car and relaxed purple-blue van: Affective qualities predict color appropriateness for car types. Journal of Consumer Behaviour, 11(5), 368-380.

Hill, R. A., \& Barton, R. A. (2005). Red enhances human performance in contests. Nature, 435(7040), 293-293.

Jacobs, K. W., \& Hustmyer, F. E. (1974). Effects of four psychological primary colors on GSR, heart rate and respiration rate. Perceptual and Motor Skills, 38(3), 763-766.

Jacobs, L., Keown, C., Worthley, R., \& Ghymn, K.-I. (1991). Cross-cultural colour comparisons: Global marketers beware! International Marketing Review. 
Jaeger, B., Sleegers, W. W., Evans, A. M., Stel, M., \& van Beest, I. (2019). The effects of facial attractiveness and trustworthiness in online peer-to-peer markets. Journal of Economic Psychology, 75, 102125.

Jiang, Y., \& Wang, C. L. (2006). The impact of affect on service quality and satisfaction: The moderation of service contexts. Journal of Services Marketing, 20(4), 211-218.

Lee, A. H., Denizci Guillet, B., \& Law, R. (2018). Tourists' emotional wellness and hotel room colour. Current Issues in Tourism, 21(8), 856-862.

Lee, S., \& Rao, V. S. (2010). Color and store choice in electronic commerce: The explanatory role of trust. Journal of Electronic Commerce Research, 11(2), 110-126.

Leow, W. K., \& Li, R. (2004). The analysis and applications of adaptive-binning color histograms. Computer Vision and Image Understanding, 94(1-3), 67-91.

Lin, I. Y. (2009). The combined effect of color and music on customer satisfaction in hotel bars. Journal of Hospitality Marketing \& Management, 19(1), 22-37.

MacQueen, J. (1967). Some methods for classification and analysis of multivariate observations. Proceedings of the Fifth Berkeley Symposium on Mathematical Statistics and Probability, 1(14), 281-297. Oakland, CA, USA.

Madden, T. J., Hewett, K., \& Roth, M. S. (2000). Managing images in different cultures: A cross-national study of color meanings and preferences. Journal of International Marketing, 8(4), 90-107.

Mehta, R., \& Zhu, R. J. (2009). Blue or red? Exploring the effect of color on cognitive task performances. Science, 323(5918), 1226-1229.

NBC New York. (2019, April 5). Survey Names New York City as the World Capital of Excitement-And Ghosting! Retrieved April 14, 2021, from NBC New York website: https://www.nbcnewyork.com/news/local/survey-names-new-york-cityworld-capital-excitement-ghosting-nyc/1108714/

Ngo, M. K., Piqueras-Fiszman, B., \& Spence, C. (2012). On the colour and shape of still and sparkling water: Insights from online and laboratory-based testing. Food Quality and Preference, 24(2), 260-268.

Phillips, W. J., \& Jang, S. (2010). Destination image differences between visitors and nonvisitors: A case of New York city. International Journal of Tourism Research, 12(5), 642-645.

Puccinelli, N. M., Chandrashekaran, R., Grewal, D., \& Suri, R. (2013). Are men seduced by red? The effect of red versus black prices on price perceptions. Journal of Retailing, 89(2), 115-125.

Siamionava, K., Slevitch, L., \& Tomas, S. R. (2018). Effects of spatial colors on guests' perceptions of a hotel room. International Journal of Hospitality Management, 70, 8594.

Thompson, D. (2018, February 17). Airbnb and the Unintended Consequences of "Disruption." Retrieved April 14, 2021, from The Atlantic website: https://www.theatlantic.com/business/archive/2018/02/airbnb-hotelsdisruption/553556/

Thompson, E., Palacios, A., \& Varela, F. J. (1992). Ways of coloring: Comparative color vision as a case study for cognitive science. Vision and Mind: Selected Readings in the Philosophy of Perception, 351-418.

Wilson, G. D. (1966). Arousal properties of red versus green. Perceptual and Motor Skills, 23(3, PT. 1), 947-949. https://doi.org/10.2466/pms.1966.23.3.947

Wu, C.-S., Cheng, F.-F., \& Yen, D. C. (2008). The atmospheric factors of online storefront environment design: An empirical experiment in Taiwan. Information $\mathcal{E}$ Management, 45(7), 493-498. 
Yildirim, K., Akalin-Baskaya, A., \& Hidayetoglu, M. L. (2007). Effects of indoor color on mood and cognitive performance. Building and Environment, 42(9), 3233-3240.

Yüksel, A. (2009). Exterior color and perceived retail crowding: Effects on tourists' shopping quality inferences and approach behaviors. Journal of Quality Assurance in Hospitality \& Tourism, 10(4), 233-254.

\section{APPENDIX}

Annex 1 . The influence of color type, saturation, and value on guest ratings

\begin{tabular}{|c|c|c|c|c|c|}
\hline Variables & $\mathrm{DF}$ & Type III SS & Mean Square & F Value & $\operatorname{Pr}>F$ \\
\hline Color type & 5 & 1531.11 & 306.22 & 3.65 & 0.0027 \\
\hline Saturation & 1 & 103.39 & 103.39 & 1.23 & 0.2672 \\
\hline Saturation $\times$ Color type & 5 & 1139.66 & 227.93 & 2.71 & 0.0186 \\
\hline Value & 1 & 265.65 & 265.65 & 3.16 & 0.0753 \\
\hline Value $\times$ Color type & 5 & 361.97 & 72.39 & 0.86 & 0.5056 \\
\hline Saturation $\times$ Value & 1 & 3.65 & 3.65 & 0.04 & 0.8348 \\
\hline Saturation $\times$ Value $\times$ Color type & 5 & 448.31 & 89.66 & 1.07 & 0.3760 \\
\hline Saturation $^{2}$ & 1 & 21.41 & 21.41 & 0.25 & 0.6136 \\
\hline Saturation $^{2} \times$ Color type & 5 & 401.35 & 80.27 & 0.96 & 0.4434 \\
\hline Saturation ${ }^{2} \times$ Value & 1 & 377.67 & 377.67 & 4.50 & 0.0339 \\
\hline Saturation $^{2} \times$ Value $\times$ Color type & 5 & 962.54 & 192.51 & 2.29 & 0.0430 \\
\hline Value $^{2}$ & 1 & 732.00 & 732.00 & 8.72 & 0.0032 \\
\hline Value $^{2} \times$ Color type & 5 & 942.49 & 188.50 & 2.24 & 0.0471 \\
\hline Saturation $\times$ Value $^{2}$ & 1 & 167.06 & 167.06 & 1.99 & 0.1584 \\
\hline Saturation $\times$ Value $^{2} \times$ Color type & 5 & 1252.60 & 250.52 & 2.98 & 0.0107 \\
\hline Saturation $^{2} \times$ Value $^{2}$ & 1 & 411.55 & 411.55 & 4.90 & 0.0268 \\
\hline Saturation $^{2} \times$ Value $^{2} \times$ Color type & 5 & 1216.53 & 243.31 & 2.90 & 0.0128 \\
\hline
\end{tabular}

Note: Saturation and value were mean-centered. 